\title{
Review Paper: The Revolution in the Iranian Disaster Management System in Controlling COVID-19 Pandemic
}

\author{
Ali Mohajervatan ${ }^{1}$ (D,Fatemeh Rezaei ${ }^{{ }^{* *}}$ (D) \\ 1. Department of Health in Disaster and Emergencies, School of Management and Medical Information Sciences, Isfahan University of Medical \\ Sciences, Isfahan, Iran. \\ 2. Social Determinants of Health Research Centre, Department of Health in Disasters and Emergencies, School of Management and Medical \\ Information, Isfahan University of Medical Sciences, Isfahan, Iran.
}

\begin{tabular}{|l|l|}
\hline $\begin{array}{c}\text { Use your devic to scan } \\
\text { and read the article online }\end{array}$ \\
Pandemic. Health in Emergencies and Disasters Quarterly. 2021; 6(4):199-204. http://dx.doi.org/10.32598/hdq.6.4.149.4 \\
doi http://dx.doi.org/10.32598/hdq.6.4.149.4
\end{tabular}

(c) (i) \$

Article info:

Received: 13 Dec 2020

Accepted: 19 Jun 2021

Available Online: 01 Jul 2021

\section{Keywords:}

COVID-19, Pandemic, Disaster, Iran, Administrative structure

\begin{abstract}
Managing the disastrous consequences of pandemics depends on the capacity of the governments to mitigate them. As the health system in Iran was undertaking economic issues because of sanctions, the government has been forced to make major and urgent decisions while anticipating the economic, social, and political effects of the COVID-19 pandemic. Therefore, Iran has integrated all critical sections of the community to provide a unified command structure to involve all stakeholders. In this regard, we present a disaster management structure in response to the COVID-19 pandemic in Iran. We hope to provide information on the advantages that might change disaster management structure in pandemics.
\end{abstract}

\section{Introduction}

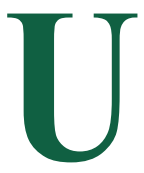

nexpected events with disastrous impacts substantially reduce communities' capabilities to respond to necessary demands [1]. The consequences of these events adversely affect human life and health [2]. Undoubtedly, the COVID-19 pandemic should be considered one of the most important events of the last century worldwide. Most countries currently face management challenges in responding to and planning for the
COVID-19 pandemic because its rapid spread has created a global crisis (62844837 confirmed cases and 1465144 deaths till December 1, 2020, reported by WHO, 2020) [3]. The managerial problems illuminate the weakness of employing evidence-based, efficient emergency plans and inappropriate utilization of new disaster management methods to deal with the disease. Because currently there is no well-established theoretical basis for responding to pandemics in the world, planning for the pandemic management is essential. Besides, the use of national and global experiences for controlling the pandemic is im-

\footnotetext{
* Corresponding Author:

Fatemeh Rezaei, PhD.

Address: Social Determinants of Health Research Centre, School of Management and Medical Information, Isfahan University of Medical Sciences, Isfahan, Iran.

E-mail:f.rezaei.ms@gmail.com
} 


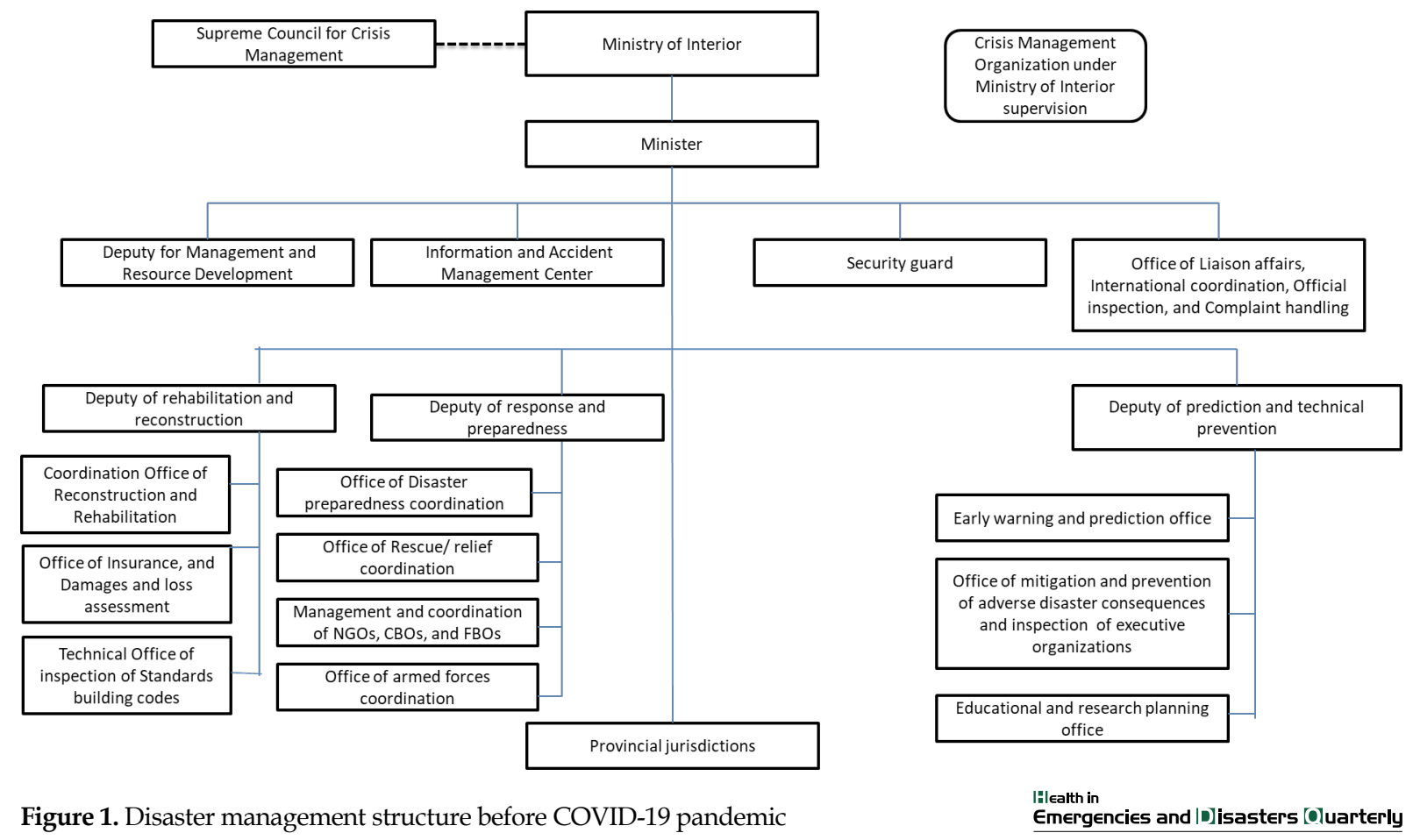

perative to achieve more practical solutions and reduce its consequences. Therefore, although adapting to global experiences is very difficult and time-consuming, authorities should provide sufficient knowledge and information to deal with the pandemic. We explain Iran's experience in responding to the COVID-19 pandemic by comparing disaster management structure before and after the pandemic.

Currently, Iran has no unified disaster management structure to cooperate with all national disaster organizations and authorities (Figure 1). Each participating organization has a specific incident command structure, objective, and strategy in response to disasters. Lack of coordination between multi-functional agencies in disasters was the main problem in previous participatory management. The National Disaster Management Organization of Iran is currently under the supervision of the Interior Ministry. The organization has direct contact with representatives of the armed forces, non-governmental organizations, and insurance organizations. In addition, the organization has well-defined responsibility in education and research in crisis, but there is no apparent connection with universities.

On the other hand, it is necessary to clearly define the connection of the Information Management Center with the command centers of Red Crescent, the Ministry of Health, and the municipalities. Finally, according to international standards, it is better to distinguish the international coordinator officer from the public liaison officer in the structure. According to Iran's disaster management law and regulations, the governor is responsible for declaring emergencies and commanding headquarters at provincial towns and counties. The Interior Minister is responsible at the national level. However, when resource mobilization is required in a crisis to integrate all response capacities across the country, and international support, the head of the executive government (President or First Deputy) is in charge of response operations (Article 11 of Iran's disaster management Law approved by the Parliament of Iran on August 25, 2019). The new law does not provide any structure for incident management where the response requires the operations of multiple organizations. Additionally, the duties of the ministries have been described separately.

Following the announcement of the first confirmed cases of COVID-19 disease in Iran, the President, as the highest government official, ordered the Ministry of Health to establish the headquarters of COVID-19 and command all ministries. The spread of the epidemic in Iran has led to the formation of a supporting headquarter consisting of tri-head officials (President, President of Parliament, and Head of the Judiciary Branch) to support the Operations Command System [4, 5]. While the Iranian government lack enough experience in crisis planning and management, the division and delegation of responsibilities to the commanding and supporting headquarters have made it possible that government, humanitarian and military agencies work together effectively (Figure 2). It should be noted that as the current 


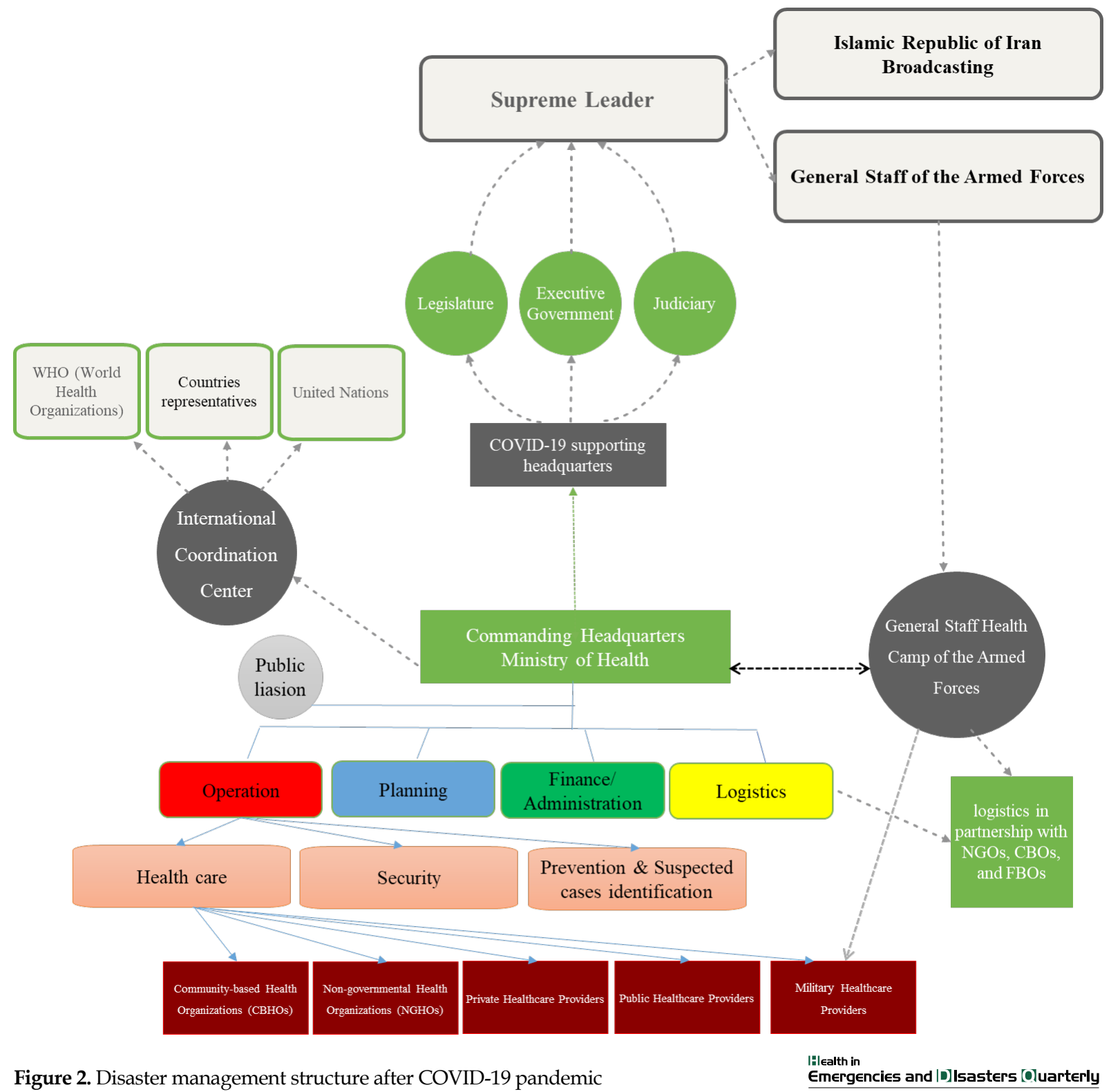

disaster is a pandemic, the commanding headquarters is the Ministry of Health. Therefore, it is better to make changes in response structures based on disaster types. The new structure (Figure 2) depicts international coordination in three sub-categories. Pandemics not only involves the World Health Organization and related United Nations organizations but also requires making connections with representatives of countries, especially neighboring countries. Another advantage of the new structure is the setting of command structure based on the Incident Command System (ICS), as it is an accepted and familiar structure for most executive departments in Iran. NGOs (Non-Governmental Organizations) and CBOs (Community-Based Organizations) participate more under the logistic branch's supervision because of less capability and readiness in epidemics. However, the Iranian army and the Red Crescent Society have high medical capacities. Therefore, they work directly under the supervision of operation branches. Besides, if any disagreement occurred between the commanding headquarter and armed forces, they would refer to supporting headquarter.

The strength of the management of the COVID-19 epidemic in Iran is due to the unity of command under the supervision of the Ministry of Health. Besides, in a higher hierarchy, a senior management system supports the command system. Taking the systemic managerial approach alongside the current health system capabilities in Iran (such as human resources, knowledge, professional commitment, etc.) has provided an opportunity for authorities to address adverse consequences of the epidemic, including idle gossips, food and equipment shortages, and the rush of people on shops (a phenom- 
enon that is common in most countries). We emphasize that unified management to respond to the COVID-19 pandemic can be achieved when all organizations and individuals across different geographical and operational areas unite under a single management structure.

The importance of delegating responsibilities will be evident when considering the political, cultural, or even religious issues, the best senior official is elected to direct all in charge of crisis managers. In other words, if all ethnic, religious, and different cultural groups cooperate with national crisis plans, political disruption will be avoided [6]. In Iran, the supreme leader and supporting headquarters are responsible for organizing the duties of all participants in a unified command. The most important advantage of crisis management during the $\mathrm{CO}$ VID-19 epidemic in Iran is that the Ministry of Health makes specialized and technical decisions while the supreme leader and supporting headquarters endorse them.

The results have also shown that applying the new organization to disaster management is an effective procedure for:

Greater coordination because of the integration of all command structures explicitly used by each organization;

Reliable estimation of urgent needs, including PPE (personal protective equipment) and personnel, because of the full participation of organizations in supplying limited resources;

Resource utilization at full capacity in unified management structure;

Assigning a single liaison officer to announce the number of new confirmed cases and death every day (spokesman of the Ministry of Health) to avoid any public confusion about the consequences of the COVID-19 pandemic;

Division of management and command posts in the new structure: the Ministry of Health holds the command headquarters, and tri-head officials support headquarters.

The application of a systematic approach in Iran has provided the opportunity to integrate civilian and military operations. The use of the military services at the operational level has two parts. First, supportive activities in that the military units participate independently or integrate with a civilian non-governmental organization (such as FBOs or NGOs). The second part includes specialized medical care provided by the military forces in health care centers. Therefore, the challenges of providing surge capacity at the local level would be solved. Finally, health authorities in Iran faced serious challenges because of the impractical Incident Action Plan (IAP). Success in using all COVID-19 pandemic control strate- gies similar to China, Russia, and Japan depends on preplanning, long-term planning, timely procurement of equipment and facilities, and our country should pave the way for practical plans $[7,8]$. This experience can benefit many countries.

\section{Ethical Considerations}

\section{Compliance with ethical guidelines}

There were no ethical considerations to be considered in this research.

\section{Funding}

This research did not receive any grant from funding agencies in the public, commercial, or non-profit sectors.

\section{Authors' contributions}

Both authors equally contributed to preparing this article.

\section{Conflict of interest}

The authors declared no conflict of interest.

\section{Acknowledgments}

The authors would like to express their gratitude to Isfahan University of Medical Sciences for supporting this study.

\section{References}

[1] Chapman K, Arbon P. Are nurses ready?: Disaster preparedness in the acute setting. Australasian Emergency Nursing Journal. 2008; 11(3):135-44. [DOI:10.1016/j.aenj.2008.04.002]

[2] Amiri M, Mohammadi G, Khosravi A, Chaman R, Arabi M, Sadeghi E, et al. [Hospital preparedness of Semnan province to deal with disasters]. Knowledge and Health. 2011; 6(3):44-50. https://www.sid.ir/en/journal/ViewPaper aspx?ID $=252519$

[3] WHO. Infection prevention and control during health care when COVID-19 is suspected: Interim guidance. Geneva: World Health Organization; 2020. https://apps.who.int/ iris/handle/10665/331495

[4] Doshmangir L, Mahbub Ahari A, Qolipour K, Azami-Aghdash S, Kalankesh L, Doshmangir P, et al. [East Asia's strategies for effective response to COVID-19: Lessons learned for Iran (Persian)]. Management Strategies in Health System. 2020; 4(4):370-3. [DOI:10.18502/mshsj.v4i4.2542]

[5] Bae Y, Joo YM, Won SY. Decentralization and collaborative disaster governance: Evidence from South Korea. Habitat International. 2016; 52:50-6. [DOI:10.1016/j.habitatint.2015.08.027] [PMID] [PMCID] 
[6] Hermansson HM. Disaster management collaboration in Turkey: Assessing progress and challenges of hybrid network governance. Public Administration. 2016; 94(2):333-49. [DOI:10.1111/padm.12203]

[7] Anderson RM, Heesterbeek H, Klinkenberg D, Hollingsworth TD. How will country-based mitigation measures influence the course of the COVID-19 epidemic? The lancet. 2020; 395(10228):931-4. [DOI:10.1016/S0140-6736(20)30567-5]

[8] Safari M, Seyedin H, Jahangiri K. Disaster risk governance in Iran: Document analysis. Journal of Education and Health Promotion. 2019; 8:142. [DOI:10.4103/jehp.jehp_30_19] [PMID] [PMCID] 
This Page Intentionally Left Blank 